\title{
Residue on Tongue Base Following Swallowing
}

National Cancer Institute

\section{Source}

National Cancer Institute. Residue on Tongue Base Following Swallowing. NCI

Thesaurus. Code C127337.

A finding of residue on tongue base following swallowing. 